\title{
AC 2011-1822: INDUSTRY EXPERIENCE AND PERSPECTIVE: A SUR- VEY OF ADVICE BRIGHAM YOUNG UNIVERSITY CAPSTONE ALUMNI SHARE WITH INCOMING STUDENTS
}

\author{
Taylor Halverson, Brigham Young University
}

Taylor Halverson earned a double major PhD at Indiana University in Instructional Technology and design and Judaism and Christianity in antiquity. He earned Master's degrees from Indiana University and Yale University. His Bachelor's degree was earned at BYU. Dr. Halverson spent several years working for Cisco in Silicon Valley where he designed creative learning experiences for thousands of customer service agents spread across the globe. Dr. Halverson currently works as a Teaching and Learning Consultant at BYU, assisting faculty members to enhance the student learning experience. He also is a part-time faculty member at BYU, teaching a variety of courses including "The History of Creativity in the Arts, Sciences, and Technology", and a part-time faculty member at Capella University, teaching online $\mathrm{PhD}$ learners in instructional technology and design. Dr. Halverson regularly presents at academic conferences and recently published a book on instructional design theory and practice.

\section{Robert H. Todd, Brigham Young University}

Robert H. Todd

Robert H. Todd is a professor of Mechanical Engineering at Brigham Young University and the founding director of BYU's Capstone program, Integrated Product and Process Design. Dr. Todd received his PhD from Stanford University in Mechanical Engineering Design, where he also received a Post Doctoral fellowship. He taught engineering courses and served in department and college administration at BYUIdaho (then Ricks College) before spending 10 years in industry in senior engineering and management positions with both the General Motors Corporation and the Michelin Tire Corporation in both the U.S. and Europe. His research and teaching interests include manufacturing process machine design, product design and the improvement of engineering education in a global setting. Since coming to BYU in 1989, he has been the senior author of two manufacturing processes books, one, Manufacturing Processes Reference Guide, a best seller used throughout the world, and more than 100 technical articles. He has served as a department chair and undergraduate coordinator at BYU, a member of the Engineering Accreditation Commission (EAC) of ABET (the Accreditation Board for Engineering and Technology). He is a recipient of BYU's Karl G. Maeser Excellence in Teaching award, the Mechanical Engineering Department's Outstanding Teacher and Rudy Awards, the department's Outstanding Achievement Award, and BYU's Blue Key College of Engineering and Technology Outstanding Faculty award. He is a member of ASME, and SAE. He is also a life member of ASEE and SME and a Fellow of the American Society for Engineering Education.

Christopher A. Mattson, Brigham Young University

Gregg M. Warnick, Brigham Young University

Gregg M. Warnick is the External Relations and Intern Coordinator for the Mechanical Engineering department in the Ira A. Fulton College of Engineering and Technology at BYU. He works directly with industry each year to recruit more than 30 funded Capstone projects and provides project management, team development, and coaching support to each of these project teams and faculty coaches. In addition, he continues to focus on increasing international project opportunities for students and faculty. His research and teaching interests include globalization, project management, leadership, ethics, and manufacturing processes. Prior to joining BYU, Gregg worked for Becton Dickinson, a Global Medical Technology Company (1995-2006). In this capacity he worked as a product development engineer, quality engineer, technical lead, business leader and program/project manager managing many different global projects. Gregg received his $\mathrm{PhD}$ in Educational Leadership and Higher Education from the University of Nebraska-Lincoln with a Master of Technology Management degree and a BS in Manufacturing Engineering Technology, from Brigham Young University. Gregg also is a Professional Associate Instructor for IPS Learning and Stanford University where he teaches the IPS course Project Management Mastery and the Stanford Advanced Project Management course Managing Without Authority for numerous fortune 500 companies throughout the world. He is a Certified Manufacturing Technologist (Society of Manufacturing Engineers) and is also certified in Planning and Managing Projects (BD University); Ethical Fitness (BD University); Lean Manufacturing (BD University); High Impact Facilitation (Lore International Institute); and Project Management (Saddle Island Institute).

(c)American Society for Engineering Education, 2011 
Industry Experience and Perspective: A Survey of Advice Brigham Young University Capstone Alumni Share with Incoming Students 
Abstract

The Brigham Young University (BYU) Capstone program is founded on project-based learning experiences. Many incoming students to the Capstone program find it challenging to make the adjustment from traditional engineering education to project-based learning in preparation for the practice of engineering in industry. Over the years, changes and innovations have been introduced into the Capstone curriculum to assist students with the transition to be successful students in this challenging, yet rewarding program. Since 1990, nearly 2,800 senior engineering and technology students have completed the two-semester Capstone course. We recognized that Capstone alumni constitute a rich source of industry experience and perspective: The alumni could highlight possible challenges and difficulties new students will face and provide relevant advice and perspective based on years of industry experience. We surveyed the alumni with two open-ended questions: (1) When you were enrolled in Capstone, what was the most difficult challenge you experienced transitioning to this project-based design course? (2) Based on your Capstone or subsequent industry experience, what recommendations do you have for helping new students do well in Capstone? Two thousand seven hundred and ninety-eight alumni received the survey and 397 responded. This paper will catalog the challenges alumni most often cited as students in transitioning to project-based learning and the associated advice, based on both their Capstone and subsequence post-graduation experience, that alumni provided to incoming students for overcoming those challenges.

\section{Introduction}

The purpose of this paper is to share feedback Brigham Young University (BYU) Capstone alumni provided concerning the challenges faced when beginning project-based learning experiences and suggestions they recommended to new students for being successful. The BYU Capstone program started in 1990 as a two-semester senior design experience. The program was developed by BYU faculty members and industry leaders to answer the needs for improved engineering education. ${ }^{1}$ From its small beginnings in 1990 of just four projects, the Capstone program has steadily expanded. As of 2010, more than 545 projects have been completed through partnerships with hundreds of domestic (U.S.) and international companies. ${ }^{2}$

The purpose of the Capstone program is to prepare students to successfully practice engineering and meet the needs of companies throughout the world to compete in a global environment. This includes the ability to engage in challenging, complex, open-ended design problems in interdisciplinary teams. Hence, Capstone is designed to mimic workforce settings. Students are assigned to complete real-world projects in small, interdisciplinary teams (typical majors represented are: Mechanical Engineering, Manufacturing Engineering Technology, and Electrical and Computer Engineering). Teams are assigned a coach (either a BYU faculty member or a local engineering professional) who mentors the teams and liaisons between the teams and the company sponsoring the assigned project. Since its inception, nearly 2,800 students have completed the Capstone course.

As successful as the Capstone program has been, many students find it challenging to make the transition from traditional instructional settings to open-ended, project-based, team-oriented learning situations. Through years of learning experiences in traditional math, science or 
engineering courses, many students have become adept at learning formulas and solving equations. But often this learning occurs devoid of the context in which such skills would be used in industrial settings. The Capstone program helps students to make that transition, but the transition can initially be quite challenging.

The challenges that students often face in the open-ended, project-based, team-oriented Capstone programs fall into four broad categories: 1) Teamwork, ${ }^{5,6}$ 2) Time management, ${ }^{7,8}$ 3) Project scope or project ambiguity, ${ }^{9,10,11}$ and 4) Lacking the full range of skills necessary for success. ${ }^{12}$ In traditional theory-oriented engineering education, teamwork and project ambiguity are rarely ingredients in the learning experience. Moreover, students are trained with specific skills they'll need to solve specific close-ended problems, not open-ended design problems. Students' ability to manage their time well is primarily the only one of the four major challenges that students have faced before entering into the Capstone program. And since teamwork and project development are some of the most important aspects of successfully completing the Capstone program, students are directly confronted with using a skill set they may not have much experience developing. Therefore, many students find the initial experiences of the Capstone program to be confounding and challenging. There are some students who still feel this way after two full semesters of Capstone experience. The instructors of the Capstone course are anxious that students can make the transition into this learning experience as smoothly and productively as possible, recognizing that most students will experience some form of growing pains. ${ }^{1,13,14}$ In an attempt to facilitate the transition, the Capstone program decided to ask former students, many that are in industry careers, to identify the challenges they had faced as Capstone students and to provide feedback to incoming students about how best to prepare for and surmount such challenges.

The remainder of this paper will explain how alumni feedback was gathered, document the major feedback trends and categories, and describe the implications of such feedback on the design of engineering courses. The hope is that the voices and experiences of alumni will provide perspective, guidance, and confidence to students entering the Capstone program. It is also hoped that the alumni feedback may be of value to other open-ended, project-based, teamoriented engineering courses and programs.

Survey instruments and responses

To learn what alumni thought about their Capstone experiences and what advice they would share with new Capstone students, a simple set of survey questions was developed:

1. In which academic year did you participate in Capstone? (e.g., 1995-1996)

2. What was your undergraduate major?

3. What is your gender?

4. What is your current professional position in industry?

5. When you were enrolled in Capstone, what was the most difficult challenge you experienced transitioning to this project-based design course?

6. Based on your Capstone or subsequent industry experience, what recommendations would you have for helping new students do well in Capstone? 
These questions were loaded into Qualtrics ${ }^{\mathrm{TM}}$ survey software. During fall 2009, 2798 alumni were invited to participate in the short survey and 397 alumni responded.

\section{Response rates}

Response rates are important element in determining the extent to which the survey data is nonbiased. Generally, higher response rates are desired. ${ }^{15}$ A recent meta-analysis of studies comparing the response rates of web surveys and paper-based surveys found a mean response rate of $34 \%$ for web surveys and $45 \%$ for paper-based surveys. ${ }^{16}$ The response rate for this survey was calculated by taking the number of complete or partial surveys returned $(n=397)$ divided by the number of surveys sent out $(\mathrm{n}=2798)$. This yielded a response rate of $14.2 \%$, which is less than the mean for web surveys, but within the range of acceptance.

Though the overall response rate was not as high as had been hoped, the hundreds of responses to the survey questions provide rich data for consideration. Still, not all surveys were fully completed. This meant that comparative statistical analyses would be much more difficult to complete (e.g., comparing male vs. female responses). Therefore, the data will be presented more in a qualitative, narrative format without an attempt to make statistical predictions. Despite the unevenness of some of the survey responses (e.g., 21 respondents did not identify their gender), this ultimately does not affect the overall research objective. The main purpose of the research was to receive advice and feedback from alumni, categorize those comments into overarching themes, and then use that thematic data to help incoming Capstone students be successful and to help make improvements to the Capstone curriculum.

Another challenge with the data is that not all respondents used the suggested program attendance dates for indicating the time period of their program (e.g., 1998-1999). Hence, some respondents indicated that they attended in 1998. Does that mean that they were part of the Capstone program for school year 1998-1999? Or does it mean that they graduated in 1998 (thus putting them into school year 1997-1998)? As a rule for interpreting the data, and without other clues for guidance, if a respondent only provided a single year format for their participation (e.g. 1998), it was assumed that the respondent participated in school year 1997-1998 and graduated in 1998 (since Capstone is a two-semester program intended for graduating seniors). Because the purpose of this survey was not primarily to compare alumni responses across graduations but to collect a rich body of seasoned advice to share with incoming students about successful performance in Capstone, the lack of specific dates for program participation on some of the surveys is immaterial to the overall purposes of this survey research.

\section{Survey results}

Introduction

In this section of the paper, the basic characteristics of the survey respondents will be described (insofar as the respondents shared such information) including year of graduation, current professional title, gender, and undergraduate major. After profiling the respondents, survey data related to the two substantive questions (\#5 and \#6 above) will be presented in narrative and graphic form. Additionally, selected representative quotes from alumni surveys will be shared. 


\section{Profile of respondents}

Surveys were received from a diversity of respondents across all of the Capstone graduation years (1990-2009) as well as a few surveys received from pre-Capstone year alumni (1988 and 1989). In total, 397 surveys were received with 382 respondents identifying their year of the program (see Figure 1). Though the number of responses is fewer in earlier years, that is probably best explained by the fact that fewer students participated in the Capstone program in those years. The number of students in the program in graduation year 1991 was 23. That number of students more than doubled to 61 in 1992 and doubled again in 1993 to 120 (Todd and Magleby, 1993). The program has since leveled off between 150 students and 210 students in subsequent years. As indicated earlier, some surveys had incomplete data, which will become apparent as the numbers are tallied below. Please note that " $\mathrm{n} / \mathrm{a}$ " in the figures below represents "no response." Hence, an "n/a” of 15 means that 15 of the respondents did not provide a response to that specific question. Figure 1 displays the number of respondents per year (in the middle of each bar) and the percentage that year represents of the total number of respondents to this survey (at the end of each bar).

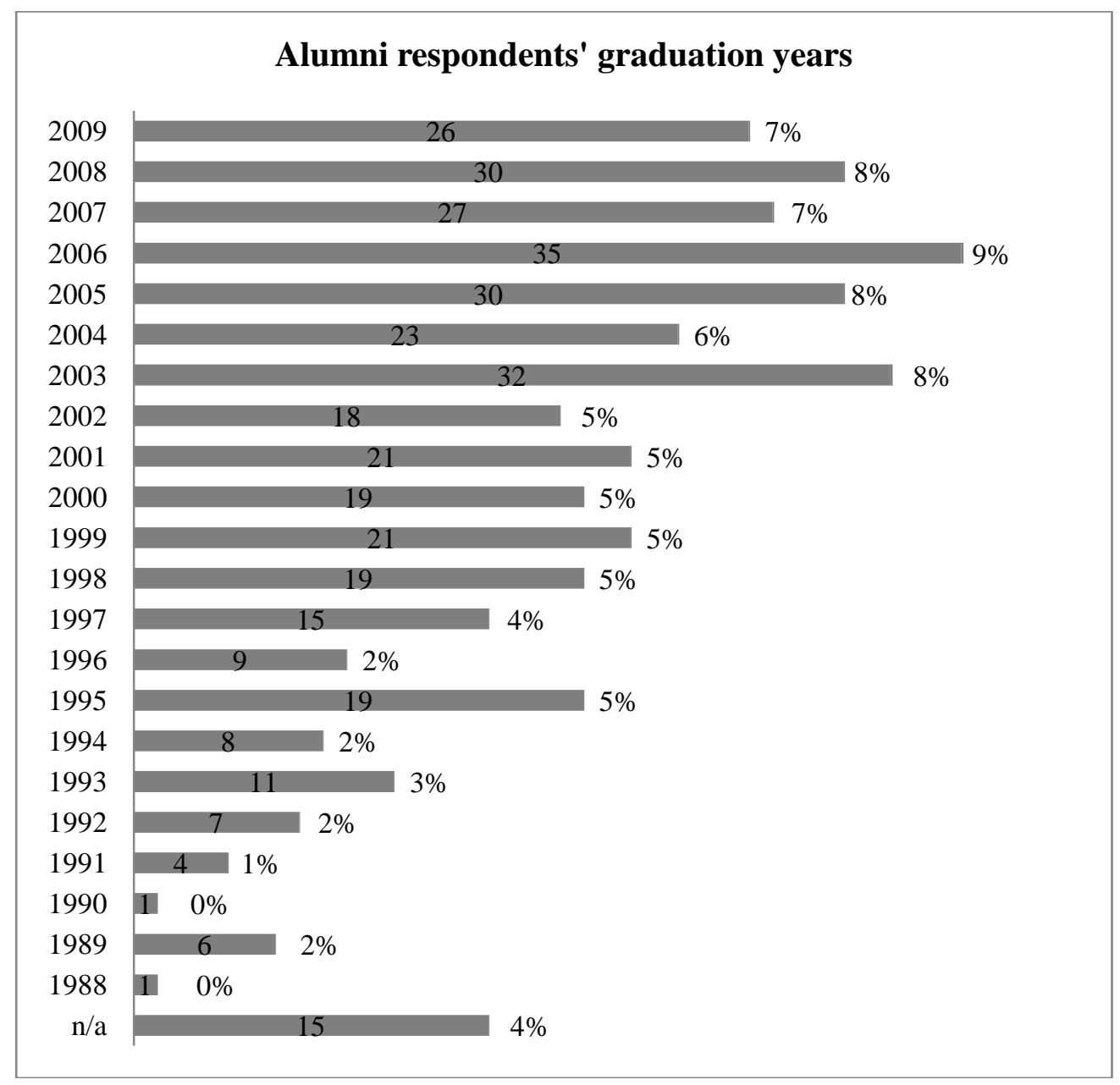

Figure 1: Alumni respondents’ graduation years 
For more than a generation, engineering programs have attempted to increase the number of women majoring in engineering. The most recent, nation-wide data from the United States, demonstrate that far more men continue to major in engineering degrees than women. In 1996, women received just fewer than $18 \%$ of the engineering bachelor degrees awarded. In 2006, the percentage of women vs. men graduating with bachelor degrees in engineering had only ticked up to $19.5 \%{ }^{17}$ The survey data of Capstone participants follow this trend; women constitute a minority percentage of engineering students. In the Capstone survey, 350 male alumni and 26 female alumni respondents reported (Figure 2). 21 respondents did not identify their gender. Even if all of the 21 non respondents were women, the total number of women completing the Capstone program would constitute less than $12 \%$ of the overall total, lower than the national average of women earning bachelor degrees in engineering. Figure 2 and subsequent figures throughout this paper display the number of respondents in a specific category (listed in the middle of each bar) and the percentage of total respondents within the figure topic area (the percentage is given to the right of each bar). Due to rounding some percentage totals may not exactly equal $100 \%$.

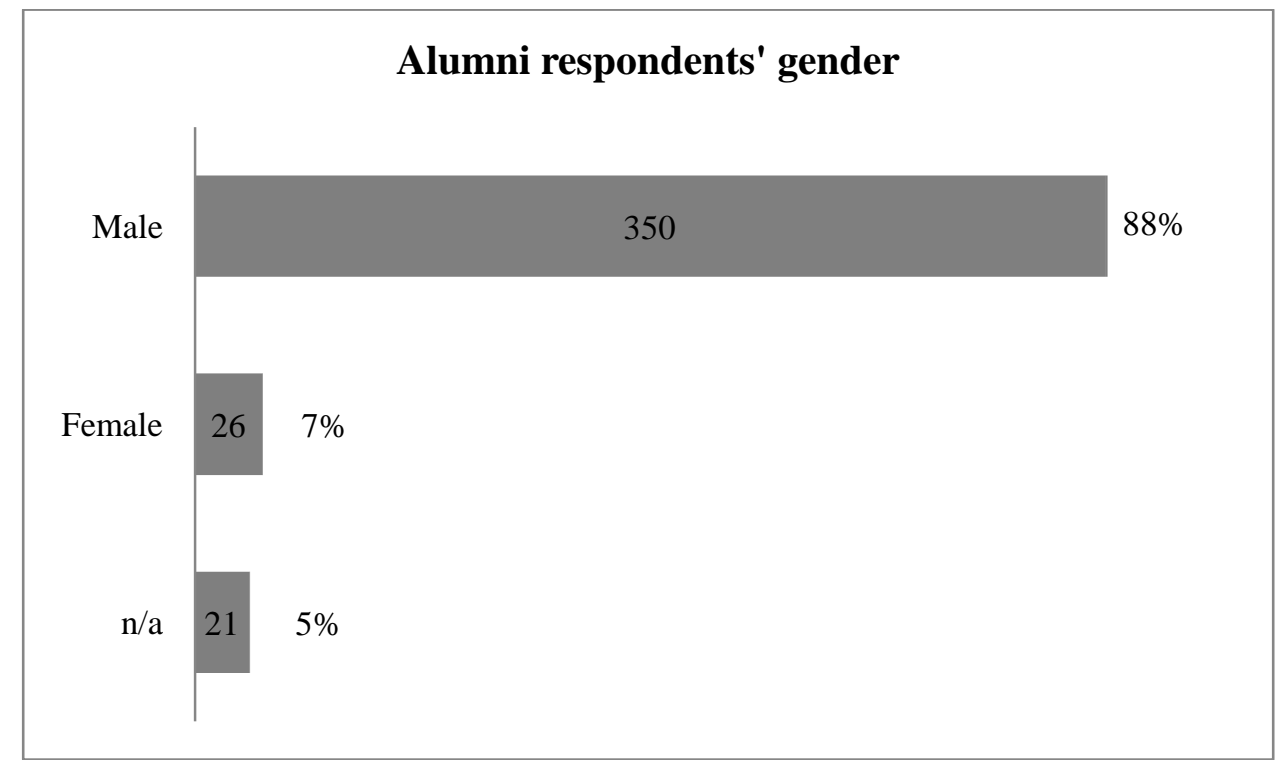

Figure 2: Alumni respondents’ gender

Alumni primarily represented the Mechanical Engineering major, which is no surprise given that the Capstone program is a requirement of all Mechanical Engineering majors at BYU. Other represented majors include Manufacturing Engineering Technology, Industrial Design, Design Engineering Technology, and Electrical Engineering (see Figure 3). All of these majors are part of BYU's College of Engineering and School of Technology. Though other majors from other campus disciplines have participated in Capstone (e.g., Biology, Business), none so reported on the survey. 


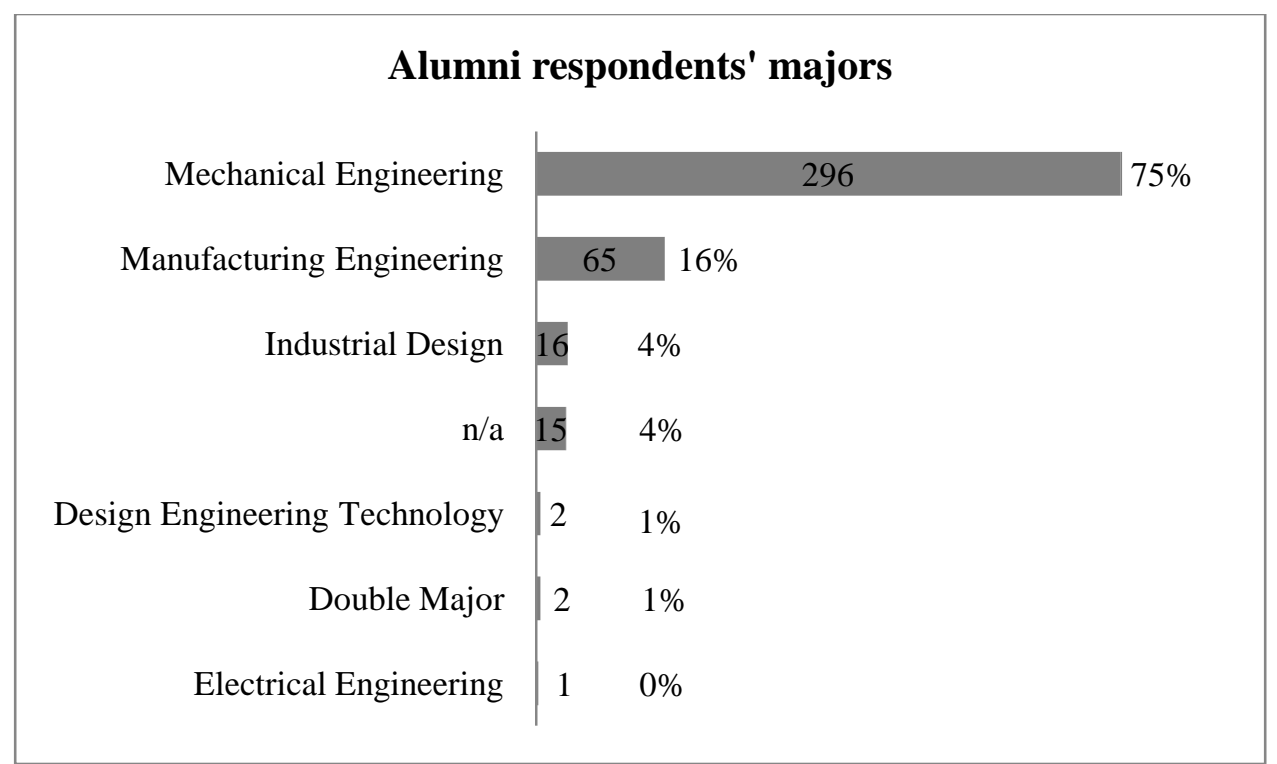

Figure 3: Alumni respondents’ majors

The survey respondents represent a diversity of life circumstances with many alumni in positions within engineering related careers. This breadth of positions represented in the list below underscore the important role that Capstone programs can play in preparing students for challenging, team-oriented work environments saturated with open-ended and ambiguous problems to be solved.

- Attorney

- Business analyst

- Business manager

- Business owner

- $\mathrm{CEO}$

- Chief engineering

- Design engineer

- Engineer

- Engineering supervisor

- Director

- Finance manager
- Global sourcing director

- Graduate student

- General contractor

- Industrial designer

- Inspector

- Logistics manager

- Mom

- Naval information warfare officer

- Network administrator
- Patent agent

- Patent writer

- Plant manager

- President

- Product developer

- Product marketing

- Professor

- Quality assurance

- $R \& D$ manager

- Research assistant

- Scientist

- Technical specialist

Having provided an overview of the survey participants, this paper will now focus on the primary reason respondents were contacted in the first place: what did they identify as the most difficult challenge they encountered and what advice would they give to incoming Capstone students? Each of these questions will be reviewed in turn.

When you were enrolled in Capstone, what was the most difficult challenge you experienced transitioning to this project-based design course? 
From 397 surveys returned 438 challenges were identified; some respondents identified multiple challenges, others none at all. By coding the responses several overarching themes appeared (see Figure 4). Alumni identified the four most difficult challenges in descending order as project scope and ambiguity $(n=157 ; 36 \%)$, teamwork $(n=140 ; 32 \%)$, time management $(n=74$; $17 \%)$, and the need for skills to be successful $(n=38 ; 9 \%)$. Some of the alumni comments fell into a final category indicating that they either were not interested in Capstone or they did not find the transition to be a challenge $(n=29 ; 6 \%)$. This last category will not be investigated here.

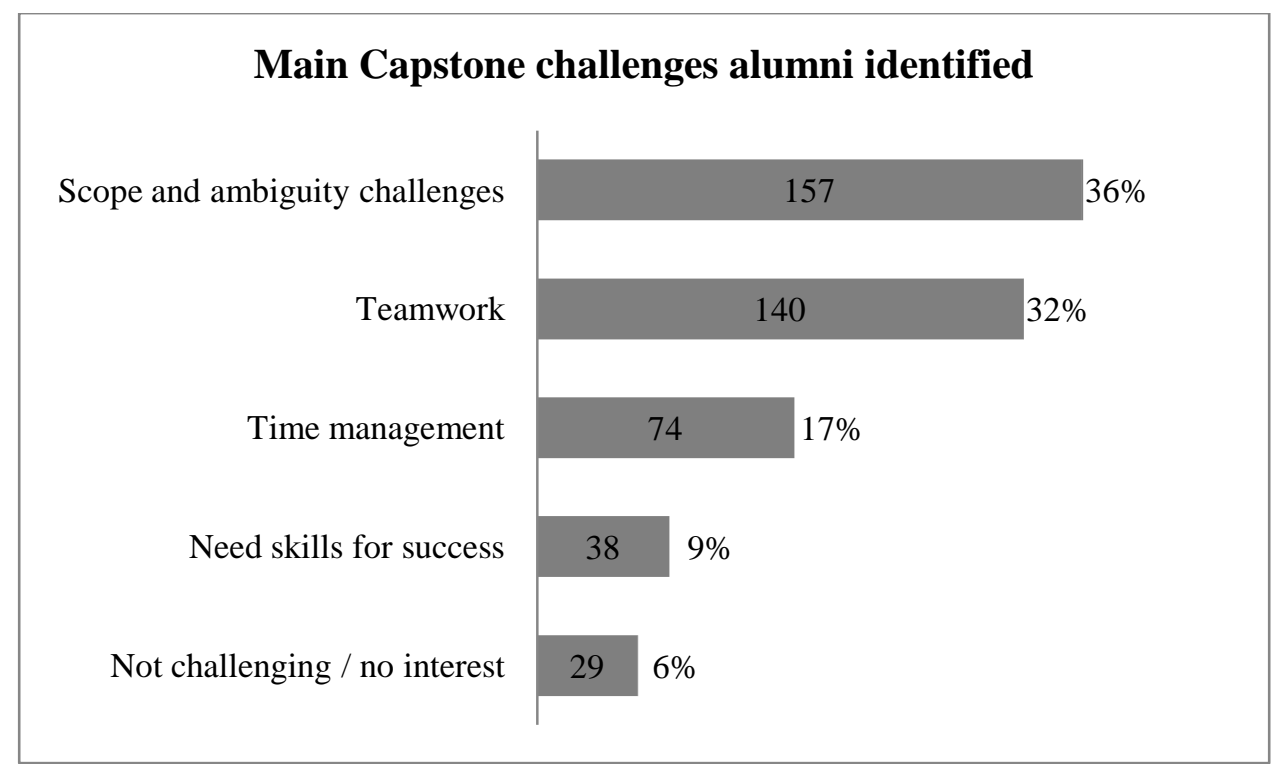

Figure 4: Main capstone challenges alumni identified

Additional review and coding of the hundreds of responses revealed additional sub-categories within the four major challenges identified. Each of these sub-categories will be explored within the context of four main challenges in the following order: Scope and ambiguity, teamwork, time management, and the skills needed for success. In the following pages, respondent data will be displayed in narrative format, followed by a graphic format for comparison purposes, and concluded with quotes from the alumni that will provide a representative perspective of alumni feedback within each sub-category. Please note that for the most part alumni comments have been quoted verbatim. Only in a few instances have changes been made to alumni comments, usually to correct spelling or minor grammatical mistakes to improve the readability of a quote.

Scope and ambiguity challenges

Project ambiguity was the most often cited challenge alumni encountered as they transitioned into the Capstone program $(n=157)$. Within the category of ambiguity, the following subcategories emerged (see Figure 5). Thirty-seven percent $(n=58)$ of the alumni discovered that the Capstone program was different than previous learning experiences. They did not have prior learning experiences from which they could meaningfully connect to this new type of learning approach. Other alumni ( $n=57 ; 36 \%)$ highlighted how difficult it was to learn and make project progress when the project was imprecisely defined, if defined at all, and customers (those 
sponsoring the project) had not clearly articulated their request. And other alumni $(n=42 ; 27 \%)$ described the complexity of balancing project demands with class demands (i.e., assignments and grades); these two aspects of the class did not always align with each other.

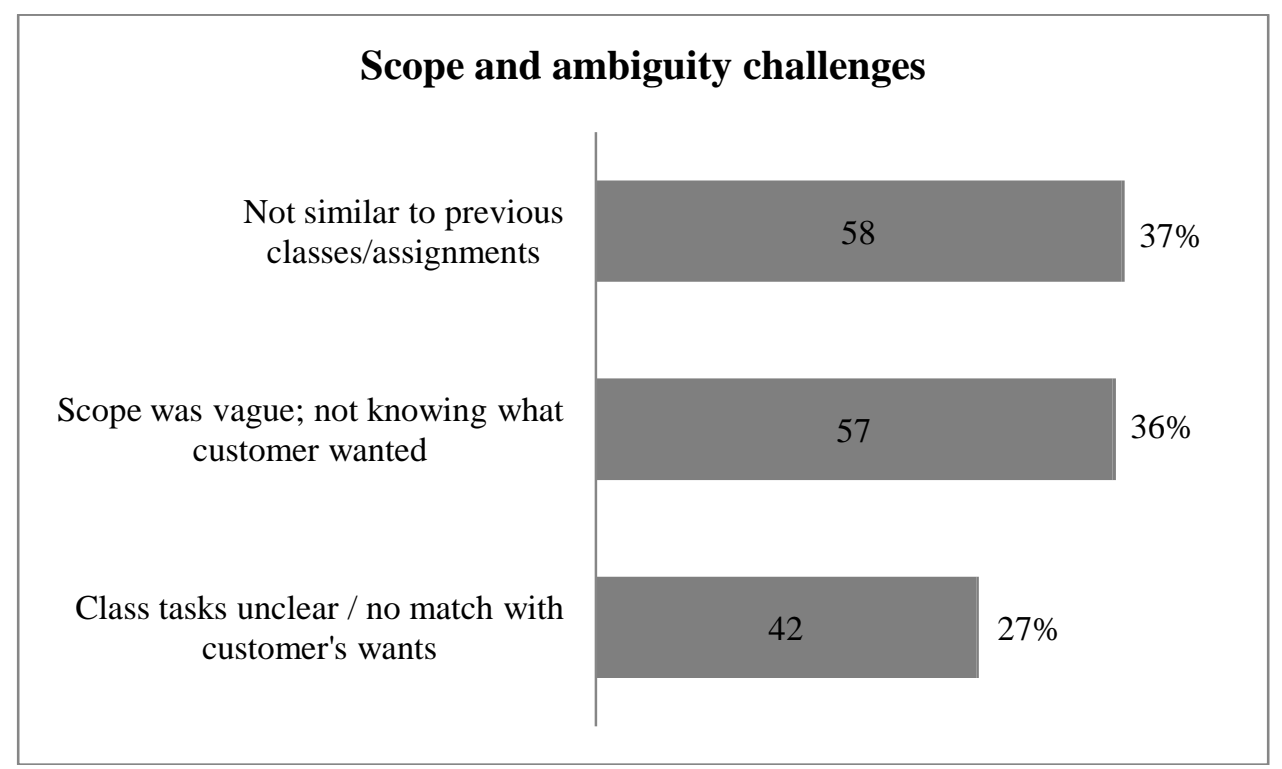

Figure 5: Scope and ambiguity challenges

Below are representative alumni comments from each of these three sub-categories:

Not similar to previous classes

"In regular classes all the problems and information are set up for you. I had never before had to think up where to find information and I had no experience in deciding WHAT to calculate or measure because text book problems do that for you. Often it's not easy to determine. Also, there's a lot of responsibility that comes with a fairly unstructured class like that. I depended on other people to do their part, and the lack of structure probably made things less efficient."

Scope was vague; not knowing what customer wanted

"The most difficult challenge was that the 'answer' was open-ended. Typically as a student the education involves solving problems that have a definite answer. The real world of engineering is so dependent upon how you frame the issue, thus it all starts with a correct vision of the beginning and the issues involved. Knowing what the customer wants is critical to providing a good solution.”

"It was always unclear what the industry partner wanted. Traditional engineering courses are well explained and the requirements known. A real-world design problem is not always clear. I remember being frustrated the whole year in Capstone because I never knew what the company really wanted from us. And I was the team leader.”

Class tasks unclear / no match with customer's wants 
"Constraining the scope of the project as outlined and envisioned by the customer to the focus of the course. The course had deadlines and milestones that didn't really fit our project, and it became difficult to please the customer while still staying on course with the class."

\section{Teamwork}

Nearly as a challenging to deal with as project ambiguity was the challenge of teamwork. Virtually all students are familiar and comfortable with independent learning. Hence, it can be rather disconcerting to then transition to a high stakes environment where a course grade and project success are inextricably linked to how well others perform and to how well a team gets along. Alumni comments $(n=140)$ clustered around three sub-categories related to the challenge of teamwork (see Figure 6). Overwhelmingly 58\% $(n=82)$ of the alumni comments related to the challenging of teamwork describe that teamwork itself was a significant challenge to successfully and happily transitioning from being an independent learner (traditional educational approaches) to being an interdependent learner (open-ended, project-based learning like the Capstone program). Other comments focused on the frustrations of aligning everyone's personal schedules with class and project requirements and deadlines $(n=29 ; 21 \%)$, while other alumni highlighted specifically that teamwork inequality (i.e., team members not carrying their weight, not performing as well as others, producing inferior work in relation to that of other team members) was the major headache to endure during their Capstone program $(n=29 ; 21 \%)$.

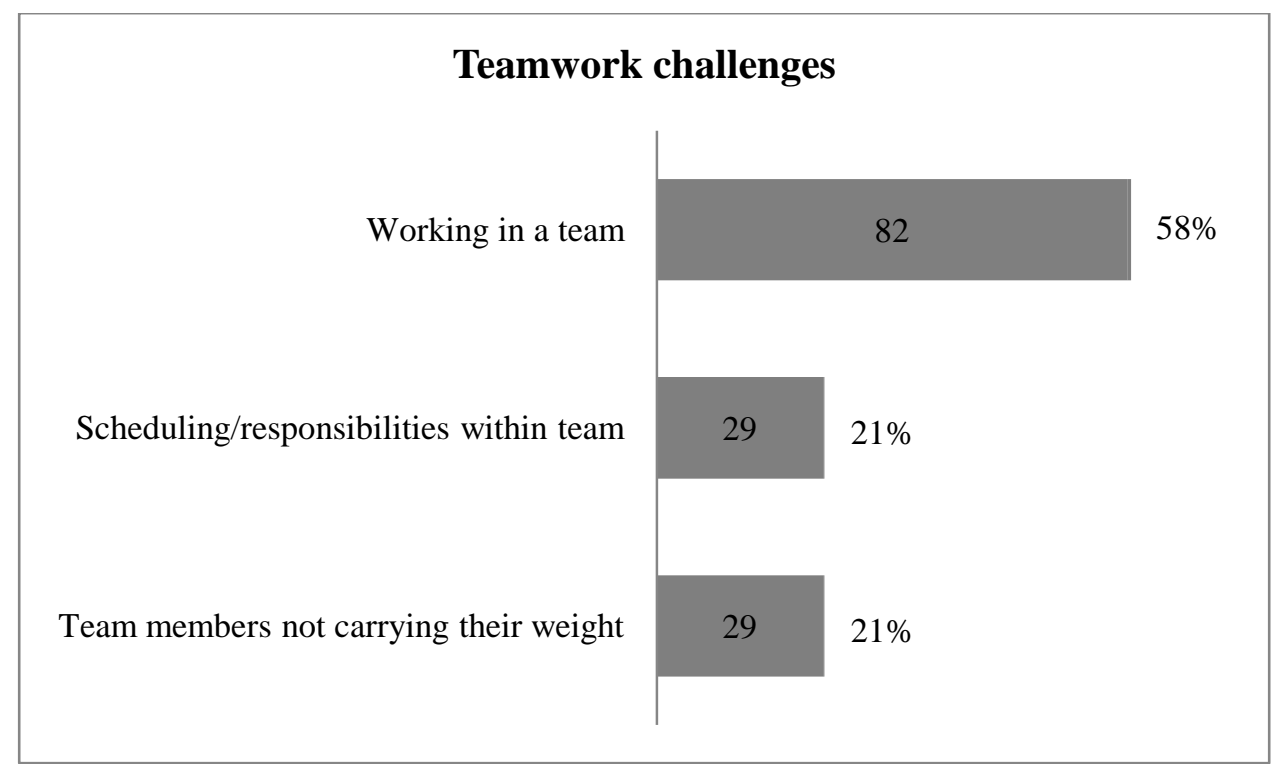

Figure 6: Teamwork challenges

The survey gathered important feedback from alumni in this category. Below are representative comments from each of the "Teamwork challenges" sub-categories:

Working in a team

"The most difficult challenge for me was getting a group of very diverse individuals to work together on our project. At times, it felt like we were almost working AGAINST each other. 
This experience has proven invaluable in dealing with very diverse individuals in industry and getting them all to work together on projects."

"Team work. I was so used to being on my own and studying as a single person that working with a team was very difficult. Now that I have been out in industry for almost 20 years and have worked for 4 different companies, the need for each student to be in a team is more important than ever. "

Scheduling and responsibilities within a team

"As a full time student and working part time to support a family I rarely had time to work in teams for other classes. I usually worked on my own because I could work on my own schedule and at my own pace. While in the Capstone program it was a struggle to work with a team that didn't have the same priorities or constraints on their time."

Team members not carrying their weight

"Coping with unequal participation from all team members. The end product and overall project experience was greatly influenced by the need for each team member to carry a portion of the weight. It was easier to help carry another's weight when there was a clear need (work, family, class schedule, etc.) and very difficult when the reason was a lack of commitment.”

Time management

It may appear from Figure 5 above that time management issues were only a minor stumbling block for students as they transitioned to the Capstone program. However, many comments ( $\mathrm{n}=$ 74) were specifically related to how time management impacted teamwork or colluded with the difficulties of project ambiguity. For the sake of simplicity, during the data review and coding process, comments were assigned one category or another. Therefore, had comments been assigned multiple categories, the time management challenge would have risen much higher on the list of key difficulties students confronted. The sub-category breakdowns for time management challenges are nearly evenly divided (see Figure 7). Alumni identified the need to set check points while balancing all schedules (project schedules, class schedules and personal schedules) $(n=26 ; 36 \%)$. Alumni also described the importance of getting started early on the project and not waiting for ambiguities to get resolved $(n=24 ; 32 \%)$. Those who waited found that they were rushed to complete their projects. Other alumni complained that project and class requirements took far too much time to complete, especially for a 3 credit college course $(n=24$; $32 \%)$. 


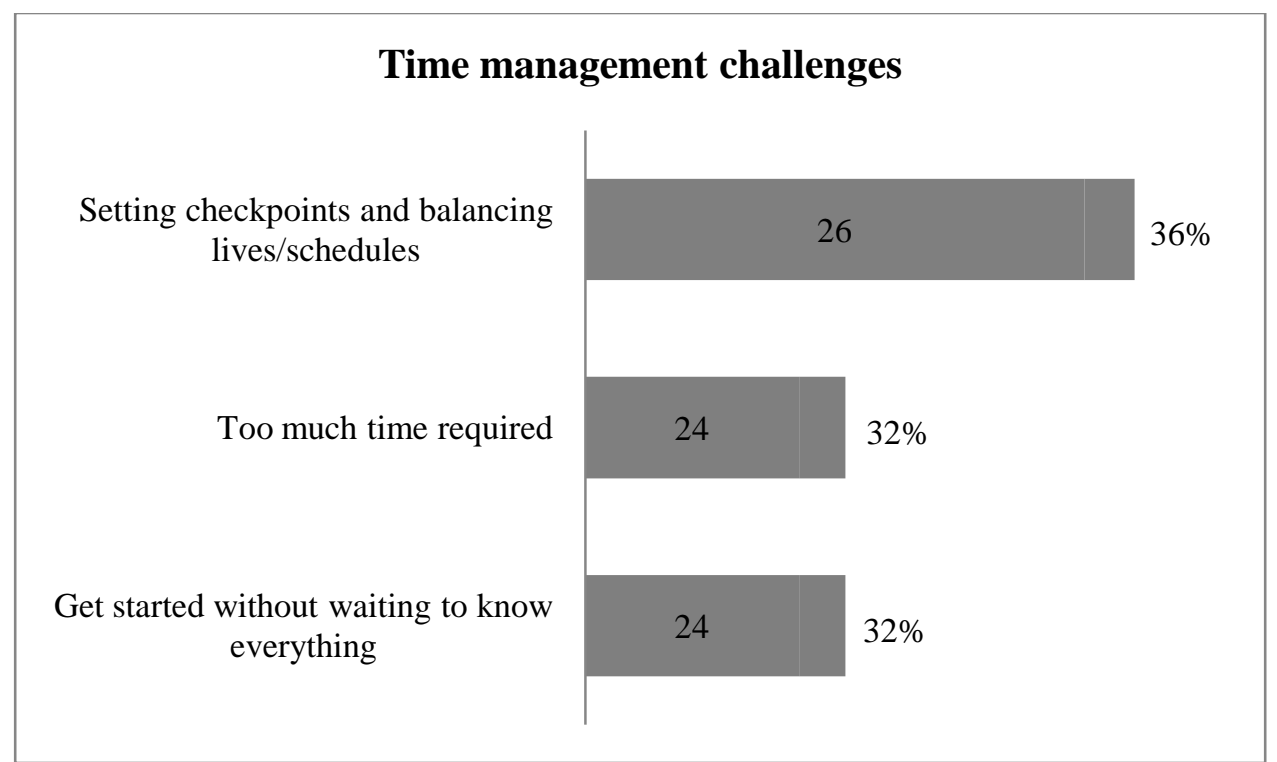

Figure 7: Time management challenges

Several key comments from the alumni are shared below for each of the "Time Management Challenges” sub-categories.

Set checkpoints and balance schedules

"The open ended frame work where so much was left to me to set timelines and deadlines in order to see the project completed on time. However, those are precisely the qualities necessary to succeed in business.”

The project and the class assignments required too much time

"Honestly, it was the time management (and sheer time) required to complete a "full-time" engineering job (the capstone) while trying to work 30 hours-per week to pay family expenses (at a real paying job). Normal university engineering "courses" required a set number of hours to complete homework and studies. A capstone engineering project is a FULL-TIME job without pay. I loved the work. I loved the class. I thought I would die with the time required to really deliver high quality engineering (balancing everything else).”

Getting started immediately

"I feel coming up to speed quickly is the most difficult challenge in any project. The sooner you can wade through the initial uncertainties, the more time it will leave at the end of a project to refine things.”

Need skills to be successful

The final major challenge category emerging from the review of Capstone alumni surveys is that students needed certain skills and capabilities training in order to be successful (see Figure 8). Though the Capstone program is designed to help students develop these skills, many alumni 
commented that they would have appreciated having these skills in advance of the program $(\mathrm{n}=$ 38). This, of course, is part of the purpose of having learners experience a Capstone program that is open-ended, project-based, and team-oriented. When learners are working in the industry, it is not unusual to find similar challenges. The two sub-category of skills needed that alumni identified were to not be put on projects for which they had no training (or to get the training in advance so that they could contribute to a project) $(n=26 ; 68 \%)$ and the overall logistics of successfully completing a project (everything from budgeting, negotiation, iterative development cycles, transportation, marketing, materials, purchasing, expectations management, etc.) ( $\mathrm{n}=12$; $32 \%)$.

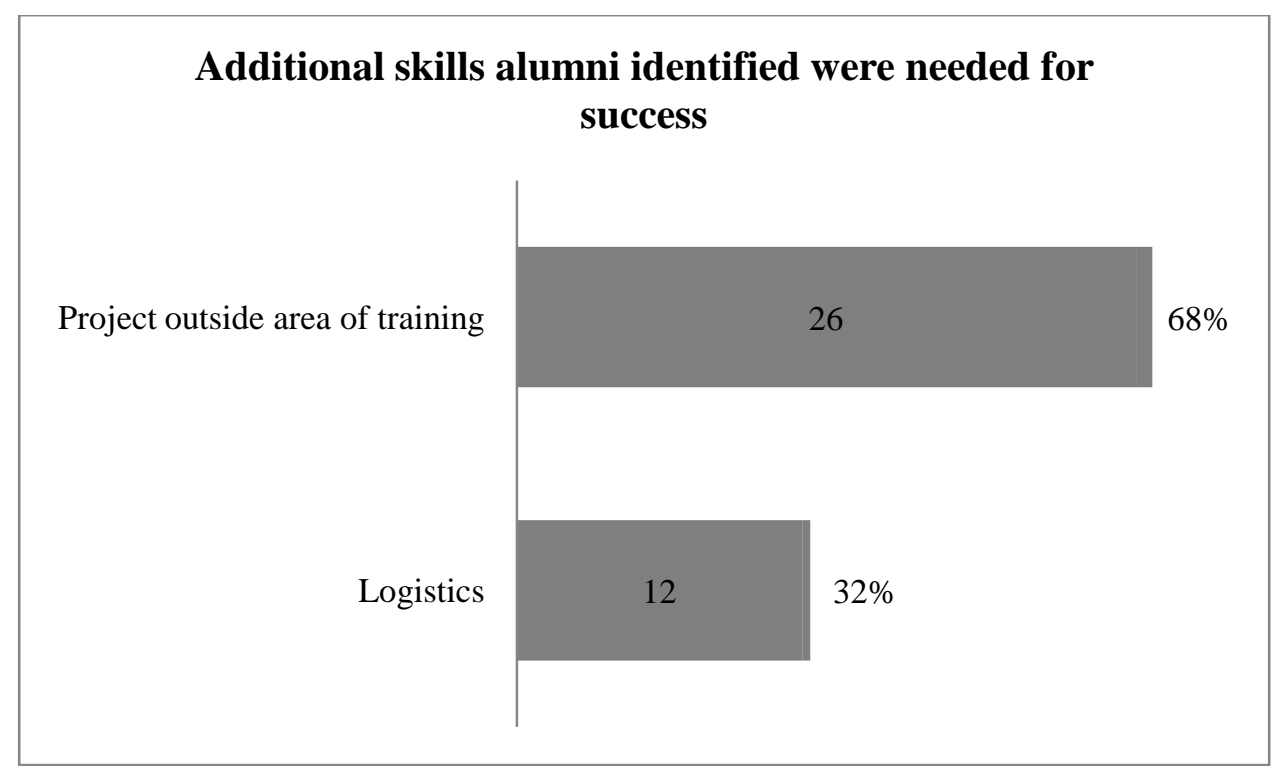

Figure 8: Additional skills alumni identified were needed for success

Representative alumni comments for each of the "Challenge of not having necessary success skills” sub-categories include:

The project was outside student's area of training

"Becoming knowledgeable of the engineering areas I was responsible (vehicle steering and suspension systems). These were not areas BYU offered instruction in.”

"My project was to invent a new process, rather than a product. It was difficult to constrain the problem and figure out how to research an area in which I had very little academic training."

"The most difficult thing was taking on tasks for which I had little instructional training. I had to learn how to do finite element analysis, not having had a course in this subject, but I learned it.”

Needed skills to navigate all aspects of project logistics

"I really struggled with the hands on part of it, setting up, doing, feeling comfortable, and experimenting with the tooling. I had been taking BYU courses for six years, and the first step I 
took into the tool shop was for my Capstone course. So much of creativity is trying it out, it would have been nice to have a lot more exposure and experience with the shop.”

“There was no approved supplier capability/contact list nor written guidance on approved purchasing methods. Finding suppliers for parts as well as knowing who can machine parts, injection mold prototypes, etc. was very time consuming along with figuring out how to get the suppliers paid.”

Having reviewed the major challenges that alumni identified in the Capstone program, the paper now turns to consider the advice and recommendations alumni provided to new students and to the designers of the program to achieve success.

Based on your Capstone or subsequent industry experience, what recommendations would you have for helping new students do well in Capstone?

Many useful suggestions were offered by alumni, some offering multiple suggestions ( $\mathrm{n}=431$ ). And this advice broke down into two main groups, suggestions to incoming students and suggestions for the program curriculum. As can be seen in Figure 9, alumni primarily concentrated their advice to new incoming students ( $\mathrm{n}=362$; 84\%), though some important considerations for curriculum improvement were offered as well ( $\mathrm{n}=69 ; 16 \%)$. Advice to students (including the many sub-categories of recommendations) will be considered first, followed by recommendations for curriculum improvement.

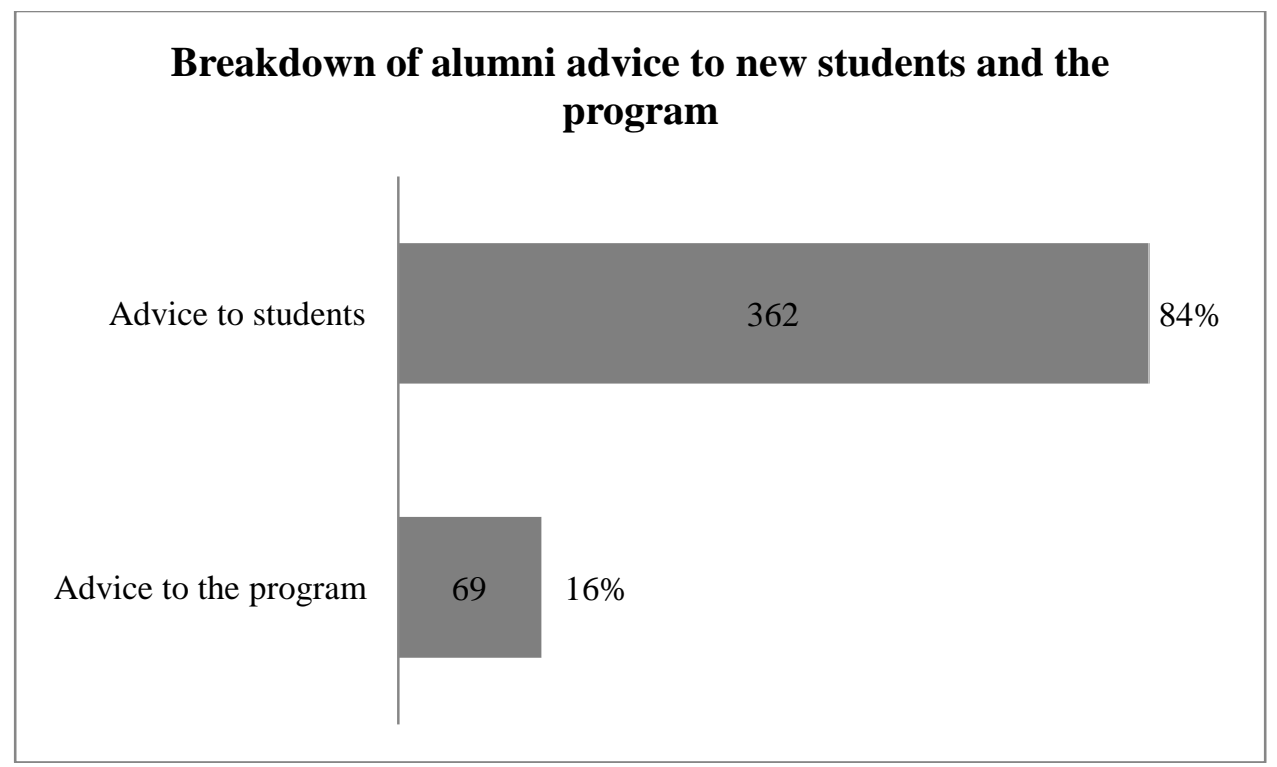

Figure 9: Breakdown of alumni advice to new students and the program

Advice to new students

Alumni advice to new students divided into four major categories and a variety of subcategories. Helpfully, three of the advice categories aligned with the challenges alumni cited (see Figure 10). For example, alumni offered suggestions on teamwork ( $n=87 ; 24 \%)$, time management $(n=85 ; 23 \%)$, and the challenge of ambiguity $(n=56 ; 15 \%)$. The remaining 
"advice to new students" category was a catchall for best practices and efficiencies ( $\mathrm{n}=134$; $37 \%$ ), perhaps representing solutions to the challenges alumni identified as skills needed for success. Each of these four "advice to new students" categories will be explored starting with teamwork, moving to time management, scope and ambiguity, and concluding with best practices recommendations.

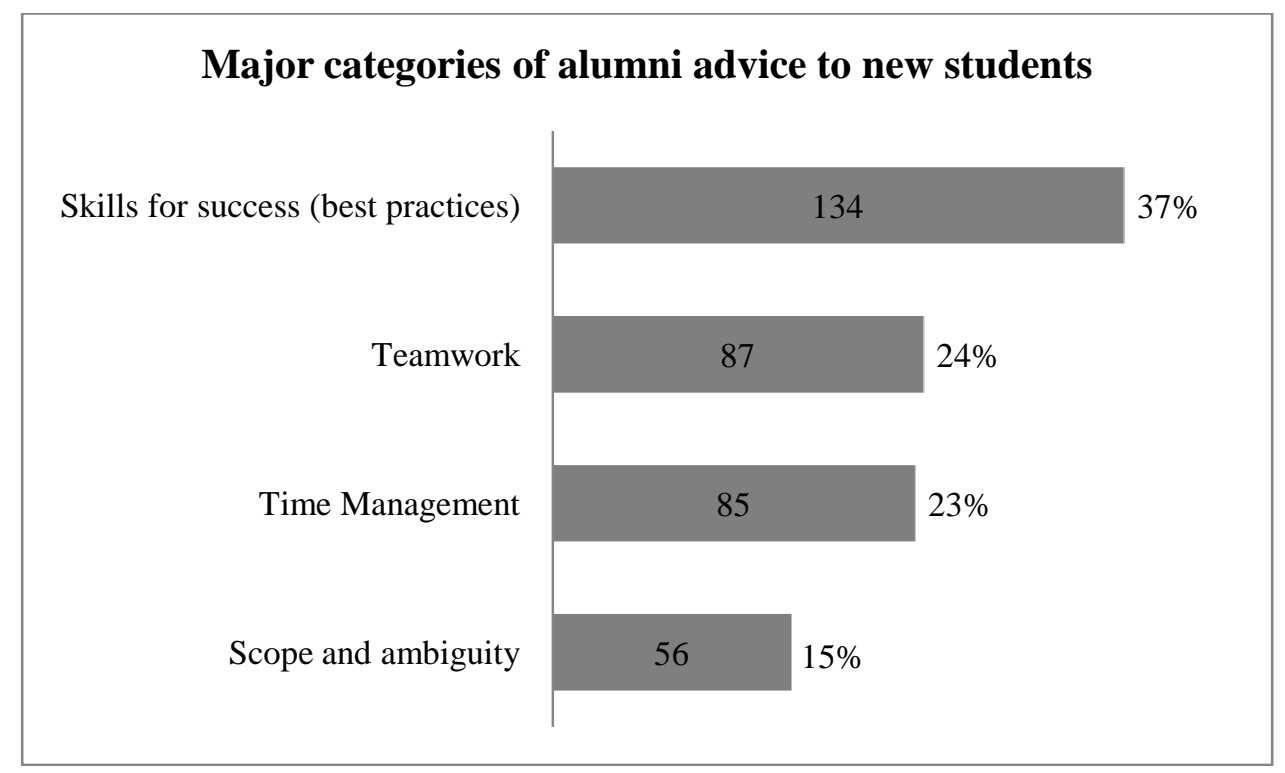

Figure 10: Major categories of alumni advice to new students

Alumni advice on teamwork

Alumni made recommendations for successful team functioning $(n=87)$ in the areas of learning to work well in a team environment ( $\mathrm{n}=47 ; 54 \%)$, communicating effectively and proactively ( $\mathrm{n}$ $=22 ; 25 \%)$, and practicing leadership skills $(\mathrm{n}=18 ; 21 \%)$ (see Figure 11$)$.

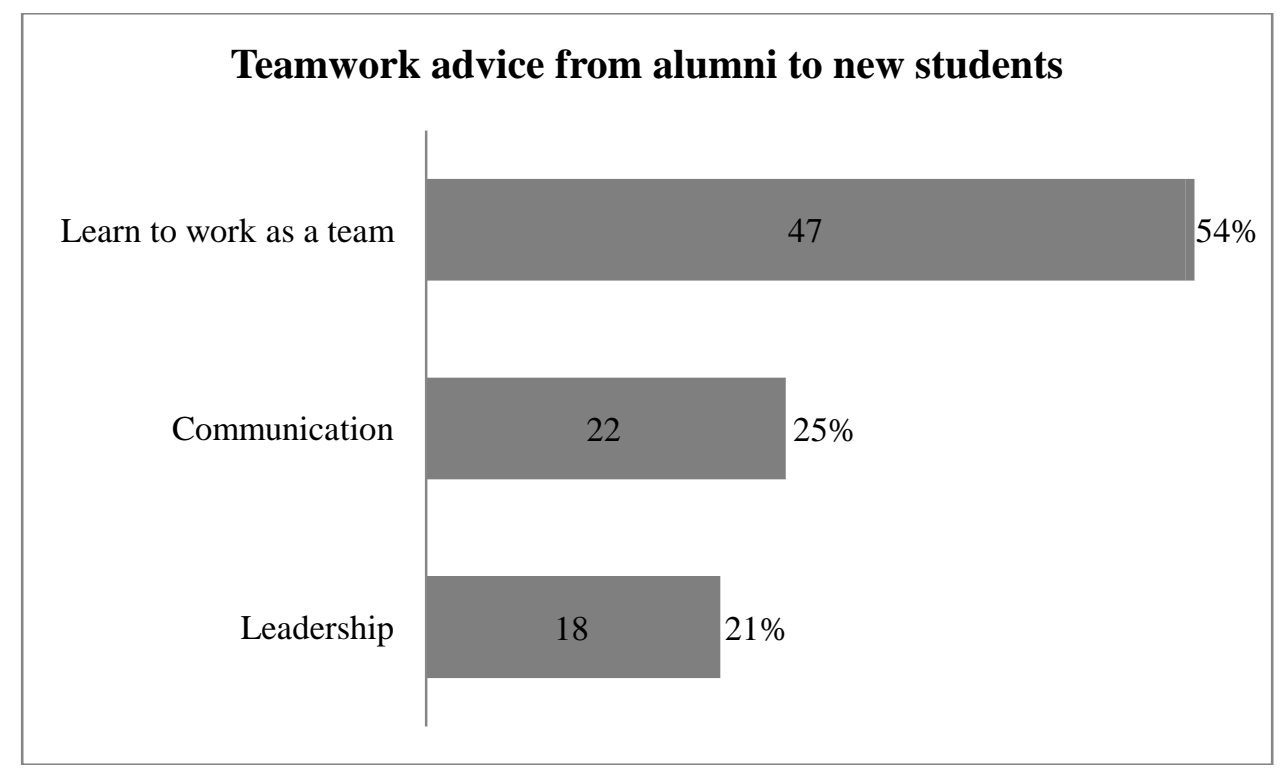

Figure 11: Teamwork advice from alumni to new students 
Representative alumni comments on how to prepare for and positively participate in team-based settings include:

Learning to work well in a team environment

"Be ready to be a team player by cooperating, participating, and being proactive. Express your ideas and be willing to consider others' ideas without bias. Work as a team and rely on one another."

"They need to understand the team dynamics and how to handle situations that arise.... Students need to know that challenges working with people are as great, and possibly greater, than the technical challenges.”

"Check up on each other and have verbal progress reports with each other. Especially in the second semester when you have to build or create your product. Better understanding each other and how that student is doing with their part of the project will enable your team to succeed. Also, knowing if someone is having a hard time finding a solution, is ok, but quickly bring it up to the team, so the best solution of help can be provided. Don't brush off other parts of the project that do not affiliate with your major, get involved with all aspects of the project.”

Communicating effectively and proactively

"Communicate, communicate, communicate! If you have a problem, technical or emotional, sit down and TALK with the person you have problem with. Both individuals need to LISTEN to what the other person is SAYING, not to the tone they say it in.”

Leadership

"Make sure that each project team has a member with outstanding leadership ability, and mentor this person in using his/her ability to serve the team. Nothing will minimize the value of a project like a lack of leadership.”

“Appoint a good team lead, let the lead make assignments, accept the assignments and complete them."

Alumni advice on time management

Alumni time management advice $(n=85)$ to new students concentrated on the areas of developing a good schedule ( $\mathrm{n}=30$; 35\%), starting early and learning from experience $(\mathrm{n}=20$; $24 \%)$, setting goals and benchmarks ( $\mathrm{n}=14 ; 16 \%)$, being aware that success will take much effort ( $\mathrm{n}=12 ; 14 \%)$, and limiting as many outside responsibilities as possible to focus on the project $(n=9 ; 11 \%)$ (see Figure 12$)$. 


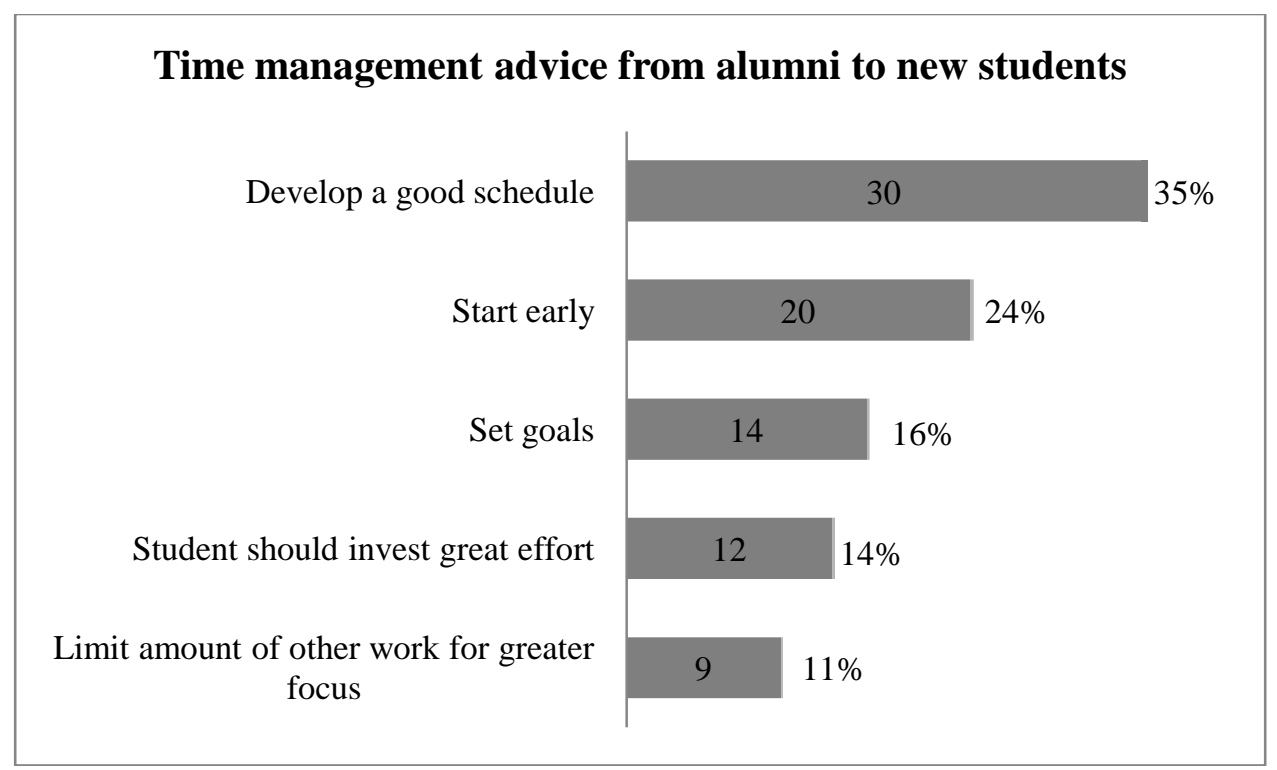

Figure 12: Time management advice from alumni to new students

The following comments represent Alumni advice on ways new students can master the skill of time management:

Developing a good schedule

"Set as many mini milestones as possible. You need to have a plan in place so that you know where you need to be at the end of the month, at the end of the week, and at the end of the day. That will help you stay focused and reach your objectives.”

Start early and learn from experience

"Planning is important but nothing is accomplished without action. Immediately start making mock ups and start testing concepts. After 3 minutes of testing you may find that the plan you spent 3 weeks on really isn't feasible. TAKE ACTION!”

"Don't get bogged down debating details in meetings. Make a goal to have your first prototype done by the end of the first month and you will learn more from that first prototype than you would from years of talking about it in meetings. This was our mistake; we spent way too much time talking."

Set goals and benchmarks

"Set small, short-term goals as you work toward the completion of an otherwise large and daunting project. Brainstorm, design, and test every component of your design in the smallest possible chunks to ensure that each performs as expected. Only then -- once you've vetted the pieces -- should you look to integrating them into the final solution/prototype.”

Be aware that success will take much effort 
"This is the most relevant to real-life work scenario activity you will do at school. Invest a lot of effort into it to see if it is something you want to do long-term. Working with people of varying skill levels and limited resources is pretty typical. The concept of just study hard on your own to get an ' $A$ ' on a test doesn't apply in the real world. Working with teams to solve a difficult problem is pretty much the norm.”

"Plan to spend a lot of hours on your project and minimize the number of intensive classes you take during your senior year. This is not the time to take 20+ credits. Also take ownership of your project whether you are the team leader or not."

Limit as many outside responsibilities as possible to focus on the project

"Develop a plan that will allow you to be flexible in the time that you can dedicate to the project. If possible, reduce other non-essential activities in your life, so that you have time in your plan that is already dedicated to work on your project with your team. Maintain a balanced life during your Capstone year, and be sure to perform the responsibilities you have within your own home with your wife and children. Your Capstone experience will be very rewarding if you set some goals and develop a plan to achieve those goals.”

Alumni advice on how to deal with scope / ambiguity challenges

Within the advice category of how new students should deal with ambiguity $(\mathrm{n}=56)$, alumni suggestions fell into four areas (see Figure 13). Alumni recommended that new students should correctly define the problems they face $(n=22 ; 39 \%)$, learn to deal with uncertainty $(n=15$; $27 \%)$, put an overall development process in place $(n=10 ; 18 \%)$, but not get carried away in processes $(n=9 ; 16 \%)$.

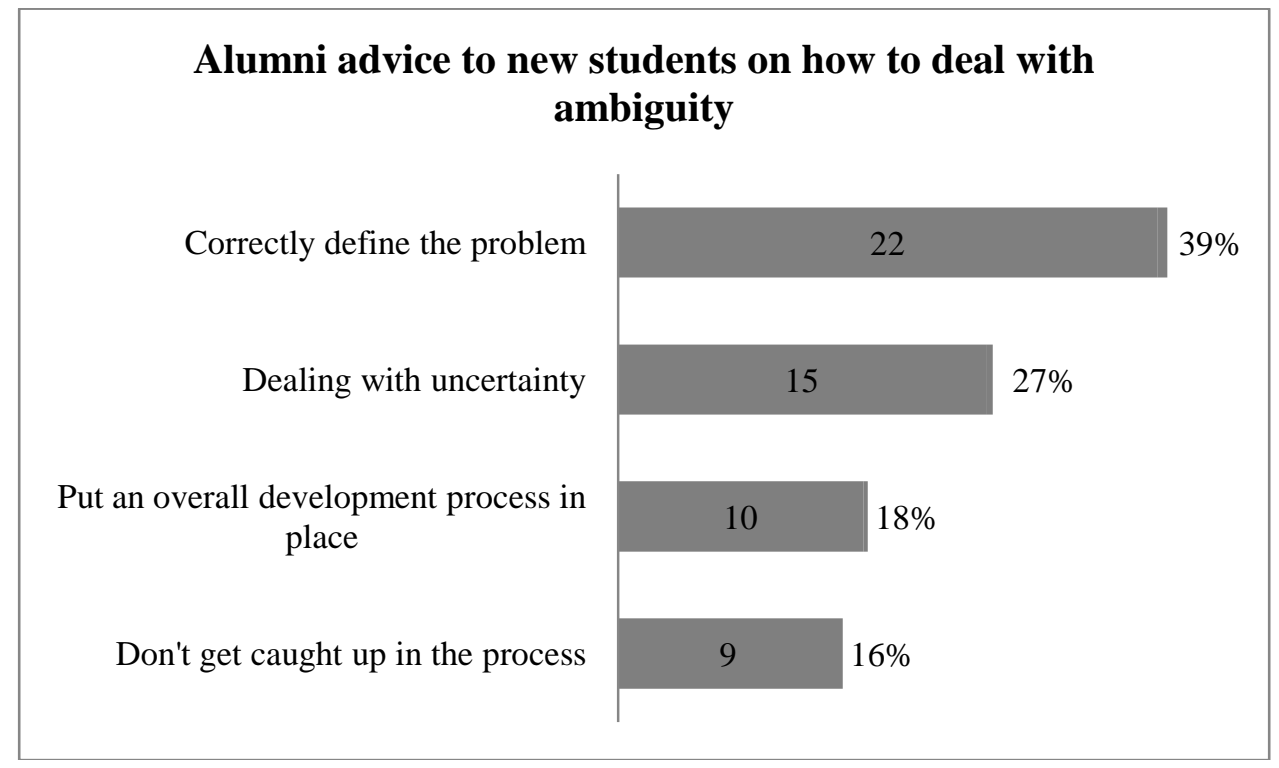

Figure 13: Alumni advice to new students on how to deal with ambiguity 
Alumni shared useful insight from their past experience and their industry perspective to help new students deal with one of the most troubling aspects of Capstone-pervasive ambiguity:

Correctly define the problems

"Take the time to correctly define the problem and get the company to buy-in on proposed solutions early on.”

"Ask a lot of questions of the sponsor to understand what they are trying to accomplish and why. Ask what they would consider an excellent final deliverable and understand why that is considered excellent.”

Learn to deal with uncertainty

"Be prepared for anything. Capstone could give you a well defined project with specific deliverables, or (in my case) it could give you an open ended project where you never really know when or if you are done. Just roll with the punches and realize you're going to graduate no matter what at this point."

"Don't be afraid to look and feel like you don't know what you're doing -- because you probably don't. I recall that a fellow team member and I had to design a gear train as part of our project. We had never done this before, but for some reason felt that, since we had already taken machine design, we were supposed to know everything we needed to do. This prevented us from asking for help and caused us to lose some valuable time. So, ask questions, and lots of them. Looking back, while our coach was an electrical engineer and couldn't have helped much with this task, we should have approached one or more Mechanical Engineering professors for help."

Put an overall development process in place

"Make sure you learn the development process, not just your project. Learn to work with others. Learn what helps and what hinders the development process. Learn the associated manufacturing processes.”

Do not get carried away in processes

"Keep the end-goal in mind: a product that is useful to the consumer. All of the steps to determine critical characteristics are important, but if they distract the team from the end-goal, then they are a negative in the process."

Alumni "best practices" advice

The remaining "advice to new students" category was a catchall for a number of best practices and efficiencies suggestions $(n=134)$ (see Figure 14). Alumni recommended that students recognize that Capstone mimics the real-world work environment $(n=36 ; 27 \%)$, use appropriate documentation practices $(n=20 ; 15 \%)$, focus on the needs of the customer $(n=19 ; 14 \%)$, seek for hands-on experiences that will build relevant skills for success $(n=16 ; 12 \%)$, seek out the 
advice of others who are knowledgeable in domains that will support Capstone success ( $\mathrm{n}=15$; $11 \%)$, focus on being innovative $(n=10 ; 8 \%)$, treat the program like a job $(n=9 ; 7 \%)$, and choose to have a good attitude $(n=9 ; 7 \%)$.

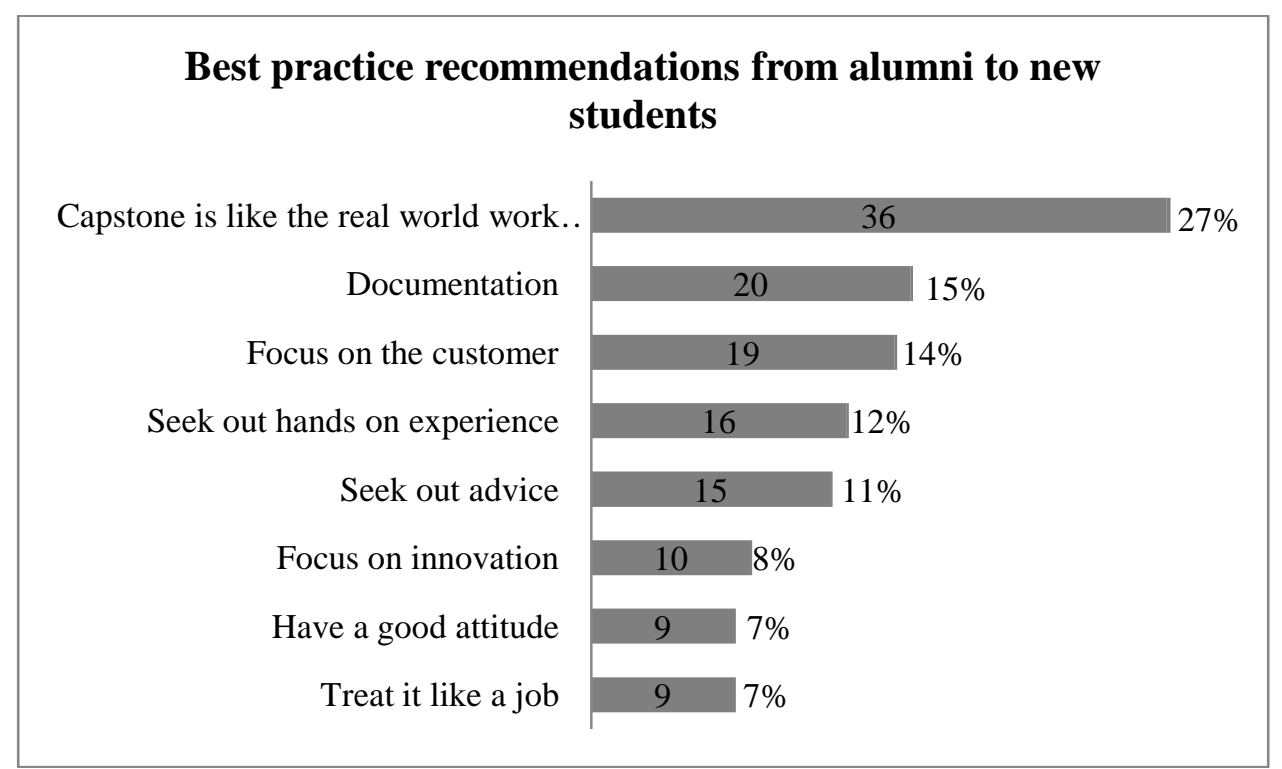

Figure 14: Best practices recommendations from alumni to new students

The alumni provided rich, practical comments on best practices gleaned from their experiences in the program and industry that any new student would do well to heed:

Recognize that Capstone mimics the real-world work environment

“Think of the project as more of an internship than a class. Use the professors as consultants.”

"Just jump into the project. In most of engineering (and most of life), you are not given well defined problem sets. You have to define the problem yourself. This is one of your first opportunities to do that. So take advantage.”

Use appropriate documentation practices

"Make sure you understand who your customer is and what their requirements and specifications are very well. Make sure that you communicate the progress of your work frequently with updates on why the schedule has changed if applicable. Learn to document your work well. Communication and proper documentation are huge in industry.”

Focus on the needs of the customer

"Well for industrial design students I'd say focus on the client. Get to know them and have healthy amounts of communication to make sure you get them something they're pleased with. It's not about the letter grade you get. It's about getting real experience working with a client to design something great within their limitations and particular criteria.” 
Seek for hands-on experiences that will build relevant skills for success

"Find people in industry that do similar thing you are trying to accomplish and ask questions. Touch something, get hands on experience in your field, then the product will be better and get done quicker.”

Seek out the advice of others

"The tasks will seem overwhelming, but they are doable. Rely on the experience of your coach and liaison to help in areas that you struggle. People appreciate hard work and dedication more than brains.”

Focus on being innovative

"Think outside the box. Look at the project not as a student but as an outsider. Learn to quickly find your own research materials and apply them to your project. You will have to do this in industry so might as well start doing it your senior year.”

Treat the program like a job

"Every individual needs to commit to pull their own weight. If your team can't depend on you to finish a task or help get things done, the team will produce suboptimal results. Do not work on homework for other classes or get distracted by personal interests (i.e. texting, email, news, Facebook, etc.) during capstone time. If you will treat this like a job, then you will find that you get much more accomplished, and your work is of higher quality. Set clear goals for each week, month, and semester. Then do everything that you can to accomplish those goals by working hard and regularly evaluating your progress. Learn to work with people who don't think like you! Project teams in industry are generally comprised of people with different personalities, interests, majors, and backgrounds. Learning to work with others is a trait that will help you not only in capstone, but in experiences throughout your life.”

Choose to have a good attitude

"Be willing to step out of your comfort zone, learn new things, take an interest in and be committed to those that are relying on you. Be a team player instead of a road block or a lead weight. It might not be fun, interesting or exciting, but it is necessary and can easily be rewarding."

Having considered many valuable suggestions from experienced and seasoned professional intended for incoming Capstone students, the paper will conclude by reviewing alumni recommendations for Capstone curriculum improvement.

Advice for the Capstone curriculum

Alumni also offered a number of compelling suggestions $(n=69)$ for improving the engineering curriculum so that students come better prepared to participate in Capstone (see Figure 15). 
Alumni proposed that the engineering curriculum do more to teach project management skills (n $=19 ; 27 \%)$, expose students to design methods earlier in the curriculum $(n=9 ; 13 \%)$, and help the students be more prepared for Capstone $(\mathrm{n}=8 ; 12 \%)$, primarily by requiring more projectbased and team-oriented work in prior classes $(n=33$; $48 \%)$.

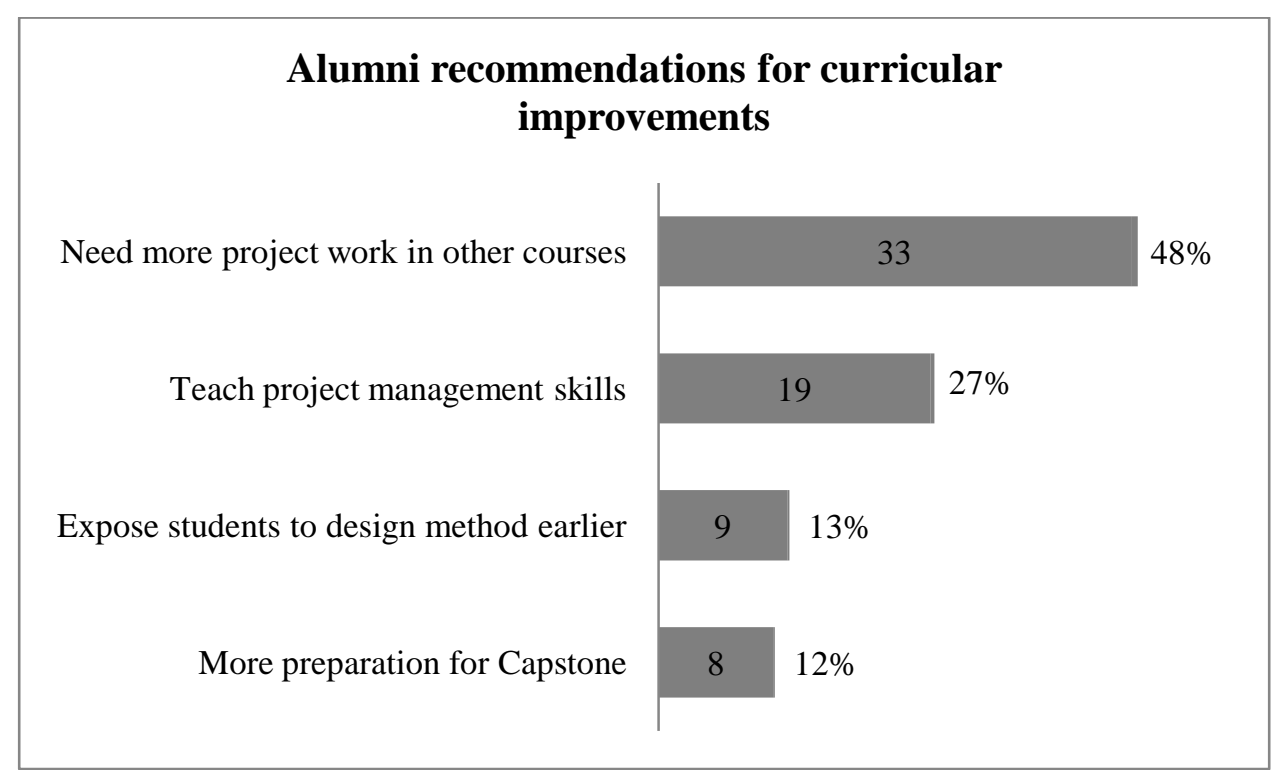

Figure 15: Alumni recommendations for curricular improvements

The following alumni comments highlight the importance of considering an aligned engineering curriculum that prepares students throughout their academic career to successfully participate in a Capstone experience:

Teach project management skills

"Focus more on business and less on the engineering. Capstone should be more about project management of people and resources while ALSO managing costs. Too few engineers understand the cost side of business and only focus on the engineering. Make the team crossfunctional with ties to students outside of the engineering school. Bring in someone from business and marketing so that everyone will learn from each other. Bring in Profit/Loss elements into the project so that the team will understand if it is going to be a worth the effort. Help the team learn about forecasting cost using volumes and using basic cost analysis methods such as net present value to determine the feasibility and profitability of the project.”

Expose students to design methods earlier in the curriculum

"To help students do well in Capstone, you could incorporate smaller design-type projects into other courses. Since a purpose of the Capstone course is to teach students how to define engineering problems and their solutions, these projects would have to be on a very small scale."

"Introduce smaller scale design problems and the tools of the design method in earlier classes in the curriculum." 
Help the students be more prepared for Capstone, primarily by requiring more project-based and team-oriented work in prior classes.

"It would be great if other Mechanical Engineering classes (200, 300 level) included more miniprojects (as opposed to just Homework problems), so that we can learn how to face, start and complete a more complex assignment earlier in the Mechanical Engineering program.”

"More application based projects and open ended problems that make people apply knowledge and tools to make educated decisions."

"More product based projects to help them prepare for Capstone. Have them develop things from concept and then analyze those concepts. It is very difficult to transition your analytical skills to practical skills and Capstone shouldn't be the first time they attempt this. Capstone should allow the students to combine these practical skills into one conglomeration project.”

Conclusion

This paper has shared the results of a large survey research study conducted in the fall 2009 of nearly 2,800 BYU Capstone alumni. Recognizing that these alumni possess years of experience and perspective derived from their own Capstone experiences and subsequent industry experience, this survey sought to tap into that wealth of knowledge to identify the major challenges new students will likely face and provide practical and relevant advice for students to face and surmount those obstacles.

Alumni identified some of the most difficult challenges incoming students may face as they transition to the Capstone learning experience. Those challenges include the ambiguous nature of project-based tasks, the complexities of working in teams, and the seemingly never-ending struggle to balance time constraints with competing demands and responsibilities (see Table 1). Though the alumni identification of these primary challenges was not revelatory - that is, project-based instructors and instructional designers have long grappled with these major issues - the alumni comments put into relief how important it is that new students be prepared for real world work environments.

\begin{tabular}{|c|c|}
\hline Challenges alumni identified & Potential solutions alumni suggested for new students \\
\hline Scope and ambiguity & $\begin{array}{l}\text { - Take time to clearly and correctly define problems. } \\
\text { Proactively solicit feedback from sponsors, coaches, and } \\
\text { professors that you have clearly defined the problems. } \\
\text { - Don't be afraid to appear as though you don't know what } \\
\text { you are doing. } \\
\text { - Ask lots of questions. } \\
\text { - Be willing to learn and to change. } \\
\text { - Learn by doing. } \\
\text { - Use processes to guide your success. } \\
\text { - Remember that you can be successful, like thousands of } \\
\text { Capstone students before you. }\end{array}$ \\
\hline
\end{tabular}




\begin{tabular}{|c|c|}
\hline Teamwork & $\begin{array}{l}\text { - } \quad \text { Be willing to take action. } \\
\text { - } \quad \text { Clarify roles, responsibilities, and obligations. } \\
\text { - } \quad \text { Learn to be an open, honest, effective, proactive, reflective } \\
\text { communicator. } \\
\text { - Appoint an effective leader for the team and support the } \\
\text { leader. }\end{array}$ \\
\hline Time management & $\begin{array}{l}\text { - Set goals and establish a schedule to work towards it. } \\
\text { - Identify the most important things to happen first and work } \\
\text { on them immediately. } \\
\text { - Minimize outside responsibilities and time commitments. }\end{array}$ \\
\hline
\end{tabular}

Table 1: Alumni identified challenges and associated potential solutions

The other major area of feedback that alumni offered related to retooling engineering education curricula. Specifically, alumni advised that engineering education programs provide students with many more project-based learning experiences in teams from the very beginning of their academic careers. True, this shifts the transition issues discussed in this paper from senior-year capstone programs to prior semesters. But the cumulative positive effective of years of projectbased learning on student competencies will be enormous. Students will be more capable to deal with ambiguity, work effectively in teams, manage their time well, and see the larger relevance of the engineering theory and principles to the world around them.

What then, in general, should be done with all of these suggestions? Beginning first with curriculum suggestions, it is clear that students who have regularly been exposed to open-ended, project-based, team-oriented learning experiences throughout their academic careers will be far more capable of making a smooth transition to a Capstone experience. Furthermore, such extended experience in industry-like learning settings will make the students more marketable graduates, and, more importantly, more successful engineers and contributors to solving problems in work or civic settings. Therefore, engineering programs, especially those that already have some Capstone experience designed into the curriculum, should consider how they might realign the requirements of prior courses to train students in the board project-based skills that they will need to succeed both in Capstone programs and later in industry.

Returning to alumni advice directed specifically to students, such knowledge should be made easily available to potential and incoming Capstone students. Perhaps these comments could be printed, by category, in a pamphlet or small booklet delivered to new Capstone students. Or perhaps these comments could be included in a searchable online database available to new Capstone students who are looking for advice from a peer, one who has already walked in their shoes. Hearing the stories, experience, and advice of those who have already walked what looks like a daunting path, can help neophyte Capstone students feel that they are not alone, recognize that the process they are embarking on is endurable, and have the confidence that they too can experience the thrill of success in a challenging environment, just as thousands of other students before them. 


\section{References}

1. Todd, R., C. Sorenson, and S. Magleby, "Designing a senior capstone course to satisfy industrial customers" Journal of Engineering Education, 1993, Vol. 82, No. 2, pp. 92-100.

2. Warnick, G., and R. Todd, "Importance of providing intellectual property to sponsoring companies when recruiting capstone projects" Capstone Design Conference, 2010.

3. Felder, R., and M. Prince, PRISM, 2007, Vol. 17, No. 2, p. 55.

4. Prince, M., and R. Felder, "Inductive teaching and learning methods: Definitions, comparisons, and research bases” Journal of Engineering Education, 2006, Vol. 95, No. 2, pp. 123-138.

5. Dutson, A., R. Todd, S. Magleby, and C. Sorenson, "A review of literature on teaching engineering design through project-oriented capstone courses” Journal of Engineering Education, 1997, Vol. 86, No. 1, pp. 1728.

6. Marin-Garcia, J., and J. Lloret, "Improving teamwork with university engineering students. The effect of an assessment method to prevent shirking" WSEAS Transactions on Advances in Engineering Education, 2008, Vol. 1, No. 5, pp. 1-11.

7. Krajcik, J., P. Blumenfeld, R. Marx, K. Bass, J. Fredricks, and E. Soloway, "Inquiry in project-based science classrooms: Initial attempts by middle school students” The Journal of Learning Sciences, 1998, Vol. 7, Nos. 3-4, pp. 313-350.

8. Thomas, J., "A review of research of project-based learning” 2000, available: http://www.bobpearlman.org/BestPractices/PBL_Research.pdf.

9. Lenschow, R., "From teaching to learning: A paradigm shift in engineering education and lifelong learning” European Journal of Engineering Education, 1998, Vol. 23, No. 2, pp. 155-161.

10. Gülbahar, Y. and H. Tinmaz, "Implementing project-based learning and e-portfolio assessment in an undergraduate course" Journal of Research on Technology in Education, 2006, Vol. 38, No. 3, pp. 309327.

11. Preuss, D., “Creating a project-based curriculum” Tech Directions, 2002, Vol. 62, No. 3, pp. 16-19.

12. Woods, D., R. Felder, A. Rugarcia, and J. Stice, "The future of engineering education. III. Developing critical skills” Chemical Engineering Education, Vol. 34, No. 2, 2000, pp. 108-117.

13. Todd, R., S. Magleby, C. Sorenson, B. Swan, and D. Anthony, "A survey of capstone engineering courses in North America” Journal of Engineering Education, 1995, Vol. 84, No. 2, pp. 165-174.

14. Todd, R., and S. Magleby, "Elements of a successful capstone course considering the needs of stakeholders” European Journal of Engineering Education, 2005, Vol. 30, No. 2, pp. 203-214.

15. Hox, J., and E. DeLeeuw, "A comparison of nonresponse in mail, telephone, and face-to-face surveys: Applying multilevel modeling to meta-analysis” Quality and Quantity, 1994, Vol. 28, No. 4, pp. 329-44.

16. Shih, T.-H., and X. Fan, "Comparing response rates from web and mail surveys: A meta-analysis" Field Methods, 2008, Vol. 20, No. 3, pp. 249-271.

17. Hill, C., C. Corbett, and A. St. Rose, Why so few? Women in science, technology, engineering, and mathematics, 2010, Washington, D.C.: American Association of University Women. 